\title{
KOMBINASI PRODUKSI OPTIMAL PADA PRODUK UD. SERAYU PEJATEN TABANAN
}

\author{
I Putu Pujanam Surya Buana ${ }^{1}$ \\ Ni Ketut Purnawati ${ }^{2}$ \\ ${ }^{1,2}$ Fakultas Ekonomi dan Bisnis Universitas Udayana (Unud), Bali, Indonesia \\ email: pujanamsuryab13@gmail.com
}

\begin{abstract}
ABSTRAK
Perencanaan produksi merupakan rangkaian aktivitas untuk menentukan dari beberapa jenis produk dengan input yang sama untuk memenuhi permintaan konsumen. Produksi yang optimal menghasilkan keuntungan yang maksimal. Tujuan penelitian ini untuk mengetahui kombinasi produksi yang optimal pada UD. Serayu di Desa Pejaten, Kecamatan Kerambitan, Kabupaten Tabanan. Penelitian ini menggunakan analisis linear programming. Berdasarkan hasil analisis linear programming dengan bantuan software POMQM for Windows didapatkan hasil untuk kombinasi produksi optimal perusahaan adalah 30,000 biji, Terakota Bata 4,536 biji, Genteng Press 24,600 biji dan Bubungan 20,400 biji. Laba bersih yang dihasilkan oleh UD. Serayu dalam produksi selama satu bulan adalah Rp.71,208,038.02 sedangkan laba bersih yang dihasilkan berproduksi pada jumlah kombinasi produk optimal adalah sebesar Rp.75,849,726.02. Analisis linear programming membantu perusahaan dalam menentukan kombinasi produksi optimal dengan adanya sumber daya yang terbatas dan analisis perhitungan laba bersih untuk membandingkan laba usaha sebelum dan sesudah kombinasi produksi optimal.
\end{abstract}

Kata kunci : optimalisasi produksi, linear programming, laba maksimal

\begin{abstract}
Production planning is series of activities to determine a production strategy to meet consumer demand. An optimal production resulting in maximum profit. The purpose of this study is to determine the optimal production combination at UD. Serayu in Pejaten Village, Kerambitan District, Tabanan Regency. This study uses linear programming analysis and analysis of calculating business net income. Based on the results of linear programming analysis using POMQM for Windows, the company's optimal production combination are 30,000 units, Terracotta Bricks 4,536 units, Pressed Roof Tile 24,600 units and Bubungan (roof) 20,400 units. The net profit generated for one month is Rp. 71,208,038.02 while the net profit generated by producing the optimal number of product combinations is $R p$. 75,849,726.02. Linear programming analysis helps companies determine the optimal production combination for limited resources and analysis of net profit helps to compare operating profits before and after the optimal production combination.

Keywords: production optimization, linear programming, maximum profit
\end{abstract}




\section{PENDAHULUAN}

Produksi merupakan salah satu kegiatan yang dilakukan oleh perusahaan untuk menciptakan suatu barang/jasa untuk di konsumsi, tujuan dari produksi adalah merencanakan dan menghasilkan output produksi yang sesuai dengan permintaan (Anugrahwaty \& Azmi, 2017). Permintaan terhadap suatu barang/jasa dapat mengalami peningkatan maupun penurunan, terjadinya ketidakstabilan permintaan pasar menyebabkan perusahaan harus memiliki perencanaan produksi (Murni et al., 2016).

Perencanaan merupakan bagian penting dalam kegiatan produksi dengan perencanaan yang tepat perusahaan dapat menentukan jumlah produksi produk (Hilman, 2016). Produksi adalah kegiatan mengolah bahan mentah menjadi bahan jadi serta menciptakan nilai tambah terhadap suatu produk dengan tujuan memenuhi kebutuhan konsumen (Ganzer et al., 2017). Perencanaan produksi merupakan rangkaian aktivitas untuk mengevaluasi produksi dimasa lalu dan sekarang serta mengantisipasi produksi dimasa mendatang untuk menentukan strategi produksi untuk memenuhi permintaan konsumen (Eunike, 2018:22). Perencanaan produksi tersebut menentukan apa, kapan dan berapa banyak produk yang harus diproduksi untuk memenuhi permintaan pelanggan dan memberikan keuntungan bagi perusahaan (Yucesan, 2017).

Perancanaan produksi merupakan sebuah kegiatan mengevaluasi data serta mengantisipasi perubahan dalam menentukan strategi produksi yang tepat untuk mewujudkan sasaran dalam memenuhi permintaan pasar secara efektif dan efisien, aktivitas ini berupa merencanakan jumlah produk yang diproduksi, material yang digunakan dalam membuat produk, kapan produk harus selesai. Menurut Putri \& Nurcaya (2020) perencanaan produksi adalah perencanaan dan pengorganisasian sebelumnya mengenai orang-orang, bahan-bahan, mesin-mesin dan peralatan lain serta modal yang diperlukan untuk memproduksi barang-barang pada suatu periode tertentu di masa depan sesuai dengan perkiraan yang diramalkan (Rizkya et al., 2019). Perencanaan produksi juga dapat didefinisikan sebagai proses untuk memproduksi barang-barang pada suatu periode tertentu sesuai dengan yang diramalkan atau dijadwalkan melalui pengorganisasian sumber daya seperti tenaga kerja, bahan baku, mesin dan peralatan lainnnya, dengan demikian perencanaan produksi merupakan pegangan untuk merancang jadwal induk produksi (Supardi, 2020)

Perusahaan yang melakukan perencanaan produksi harus mampu memperhitungkan kemampuan dan keterbatasan sumber daya yang dimiliki serta memperhatikan faktor - faktor yang mempengaruhi perencanaan produksi seperti data penjualan pada periode tahun sebelumnya, biaya produksi, pemakaian bahan, jam kerja, waktu penyelesaian produk, hal tersebut yang akan dipertimbangkan perusahaan untuk menyelesaikan permasalah keterbatasan sumber daya untuk mencapai jumlah kombinasi produksi optimal (Sinaga, 2016)

Product mix atau kombinasi produksi adalah ketentuan jumlah dan jenis produk yang harus dibuat agar diperoleh keuntungan maksimum atau biaya minum dengan memperhatikan sumber daya yang dimiliki dengan perpaduan sistem produksi barang atau jasa dalam suatu kondisi kuantitas produksi tertentu, sehingga perusahaan mampu menentukan nilai optimum dalam produksi satu atau lebih 
barang atau jasa sesuai keinginan atau permintaan konsumen (Hosseini Jey et al., 2017). Kombinasi produksi merupakan ukuran terhadap apa dan berapa banyak barang-barang yang akan diproduksi oleh suatu perusahaan, penentuan kombinasi produksi ini penting agar angka produksi dapat disesuaikan dengan angka penjualan sehingga dapat menekan biaya bahan baku agar tidak diproduksi secara percuma dan keuntungan menjadi lebih maksimal (Kim \& Glock, 2018).

Kombinasi produksi optimal dapat diperoleh perusahaan ketika memproduksi lebih dari satu macam produk dengan menggunakan bahan baku yang sama tetapi menghasilkan jumlah output produk yang berbeda - beda, tujuan kombinasi produksi optimal yaitu menggunakan sumber daya yang terbatas untuk menghasilkan produk yang sesuai dengan kapasitas produksi dan permintaan produk (Georgiadis et al., 2019). Perusahaan yang memproduksi produk lebih dari satu jenis produk dan menggunakan sumber daya yang sama maka perusahaan perlu melakukan kombinasi produksi, dimana salah satu alat analisis yang dapat digunakan oleh perusahaan dalam perencanaan produksi untuk menemukan kombinasi optimal dari keterbatasan sumber daya yang dimiliki, dengan tujuan meminimumkan biaya atau memaksimalkan laba adalah linear programming (Woubante, 2017).

Linear programming merupakan suatu teknik dari riset operasi untuk memecahkan persoalan optimasi dengan menggunakan persamaan dan pertidaksamaan linear untuk mencari pemecahan yang optimum dengan memperhatikan pembatasan - pembatasan yang ada (Salim \& Santoso, 2018). Suatu persoalan dikategorikan sebagai persoalan program linier apabila, tujuan (memaksimalkan atau meminimumkan) yang akan dicapai dinyatakan dalam bentuk persamaan fungsi linier; terdapat alternatif pemecahan persoalan program linier, dan pembatasan-pembatasan dari sumber yang tersedia dinyatakan dalam bentuk pertidaksamaan linier. Linear programming memiliki dua fungsi tujuan yaitu maksimasi laba dan juga minimasi total cost (Aprilyanti, 2019)

Linear Programming merupakan suatu metode untuk memaksimumkan atau meminimumkan permasalahan optimasi dan terbatas pada masalah yang dapat diubah menjadi fungsi linear, dimana permasalahan dalam linear programming adalah untuk menentukan besarnya masing-masing nilai variabel sehingga hasil dari fungsi tujuan yang linear menjadi optimal dengan memperhatikan fungsi kendala atau kendalakendala yang digunakan (Oladejo et al., 2019). Menurut Lauinger et al. (2016) program linier adalah suatu cara untuk menyelesaikan persoalan pengalokasian sumber-sumber yang terbatas diantara beberapa aktivitas yang bersaing, dengan cara yang terbaik, yang mungkin dilakukan. Program linier menggunakan model matematis untuk menjelaskan persoalan yang dihadapinya.

Dalam membangun model dari formulasi suatu persoalan digunakan karakteristik-karakteristik yang biasa digunakan dalam persoalan program linier, yaitu Variabel Keputusan, Fungsi Tujuan, Pembatas dan Pembatas Tanda (Oladejo et al., 2019). Variabel keputusan adalah variabel yang menguraikan secara lengkap keputusan-keputusan yang akan dibuat. Fungsi tujuan merupakan suatu hubungan linier dari variabel keputusan yang berupa fungsi maksimum atau minimum yang mana tingkat pencapaian tujuan ini dibatasi oleh kendala yang mencerminkan keterbatasan dari kemampuan kapasitas waktu produksi yang dimiliki. Pembatas 
merupakan kendala yang dihadapi sehingga kita tidak bisa menentukan harga-harga variabel keputusan secara seimbang. Koefisien dari variabel keputusan pada pembatas disebut koefisien teknologis, sedangkan bilangan yang ada disisi kanan setiap pembatas disebut ruas kanan pembatas. Pembatas tanda adalah pembatas yang menjelaskan apakah variabel keputusannya diasumsikan hanya berharga nonnegatif atau variabel keputusan tersebut boleh berharga positif, boleh juga negatif (tidak terbatas dalam tanda) (Qiu et al., 2019)

Beberapa penelitian yang mengaplikasikan linear programming untuk meminimasi total cost adalah penelitian Parlesak et al. (2016), Kimutai et al. (2019), Jain et al. (2020), Romanova (2019), Mohd Baki \& Cheng (2020), Khan \& Faisal (2021), Chandrawat et al. (2017), Du et al. (2018), Ehmke et al. (2018) dan Lauinger et al., (2016). Penelitian lainya menggunakan laba sebagai fungsi tujuan, yaitu penelitian Sadeghian \& Ardehali (2016), Indah \& Sari (2019), Wang et al. (2018), Akpan \& Iwok (2016), Krisnadewi \& Setiawan (2018) dan Sudhana (2017).

Penelitian Sudjaja \& Santoso (2018) dan Ogbeide \& Ejechi (2018) menyimpulkan bahwa model matematis dari metode optimasi secara umum dapat diaplikasikan dalam bidang teknik maupun masalah ekonomis. Salah satu dari contoh penerapan linear programming terdapat pada penelitian Supriyo (2019) mengenai penjadwalan kedatang dan keberangkatan kereta api. Linear programming tidak hanya dapat diaplikasikan pada kombinasi produksi saja, tetapi juga dapat diaplikasikan dalam bidang lain yang ada di perusahaan. Penelitian lainya dari Nazari et al. (2016) dan Baidya et al. (2016) meneliti tentang cara pengalokasian software agar bekerja dengan optimal. Pengaplikasian model matematis linear programming memberikan manfaat terhadap perusahaan untuk alternative keputusan pengalokasian sumber daya yang dimiliki oleh pihak perusahaan agar mampu mencapai suatu tujuan baik itu memaksimalkan keuntungan atau meminimumkan biaya.

UD. Serayu merupakan salah satu UMKM yang berlokasi di Banjar Dukuh, Desa Pejaten Kabupaten Tabanan yang memproduksi beberapa jenis kerajinan batu bata seperti Bata Expose Stick, Terakota Bata, Genteng Press, dan Bubungan dengan menggunakan bahan baku tanah liat. Untuk memproduksi masing - masing produk diatas memerlukan bahan baku berupa tanah liat, bahan penolong berupa pasir paras, tenaga kerja yang tersedia sebanyak delapan orang dengan jumlah jam kerja selama tujuh jam, tiga macam alat yang dipergunakan untuk proses produksi yaitu mesin pencampur dan penggiling tanah liat dengan batu paras, mesin untuk mencetak produk pada sesuai ukuran dan mesin untuk pembakaran bata sehingga siap untuk dipasarkan. Mesin - mesin yang di miliki perusahaan masih bersifat manual dimana harus ada tenaga kerja yang mengoperasikan mesin-mesin tersebut sehingga proses produksi dapat berjalan. Produksi rata-rata perbulan untuk produk Bata Expose Stick adalah sebanyak 12,000 biji, produk Terakota Bata sebanyak 14,400 biji, produk Genteng Press sebanyak 9,600 biji dan produk Bubungan sebanyak 15,600 biji. Ud serayu melakukan produksi produknya dengan dasar permintaan pelanggan tanpa pernah memperhtiungkan berapa sebenarnya kombinasi

Berdasarkan hasil wawancara dengan manajer UD. Serayu produk Bata Expose Stick merupakan produk yang paling laku dan diminati pasar, hal tersebut 
terbukti dari jumlah produksi yang lebih banyak dari pada produk bata lainnya. Harga per unit Bata Expose Stick sebesar Rp. 1,650, Terakota Bata sebesar Rp. 5,500, Genteng Press Rp. 1,100 dan Bubungan sebesar Rp. 2,500. Dengan laba per unit produk Bata Expose Stick sebesar Rp. 693, Terakota Bata sebesar Rp. 3,588, Genteng Press Rp. 525 dan Bubungan sebesar Rp. 1,604. Sebagai UMKM tentunya UD. Serayu memiliki sumber daya seperti tanah liat yang terbatas sebagai bahan baku utama dalam proses produksinya, maka dari itu perlu untuk mencoba pengalokasian sumber daya yang dimiliki secara optimal. Dilihat dari produk yang diproduksi membutuhkan sumber daya yang sama, tetapi menghasilkan jumlah produk yang berbeda. Perusahaan melakukan produksinya didasarkan oleh pesanan pelanggan tanpa mengetahui berapa sebenarnya kombinasi produksi optimal yang harus dilakukan perusahaan agar memperoleh laba yang maksimal, untuk itu perusahaan perlu menentukan kombinasi produksi dengan alat bantu linear programming untuk mengetahui kombinasi produksi optimal dengan fungsi tujuan maksimasi laba dan kendala (constraint).

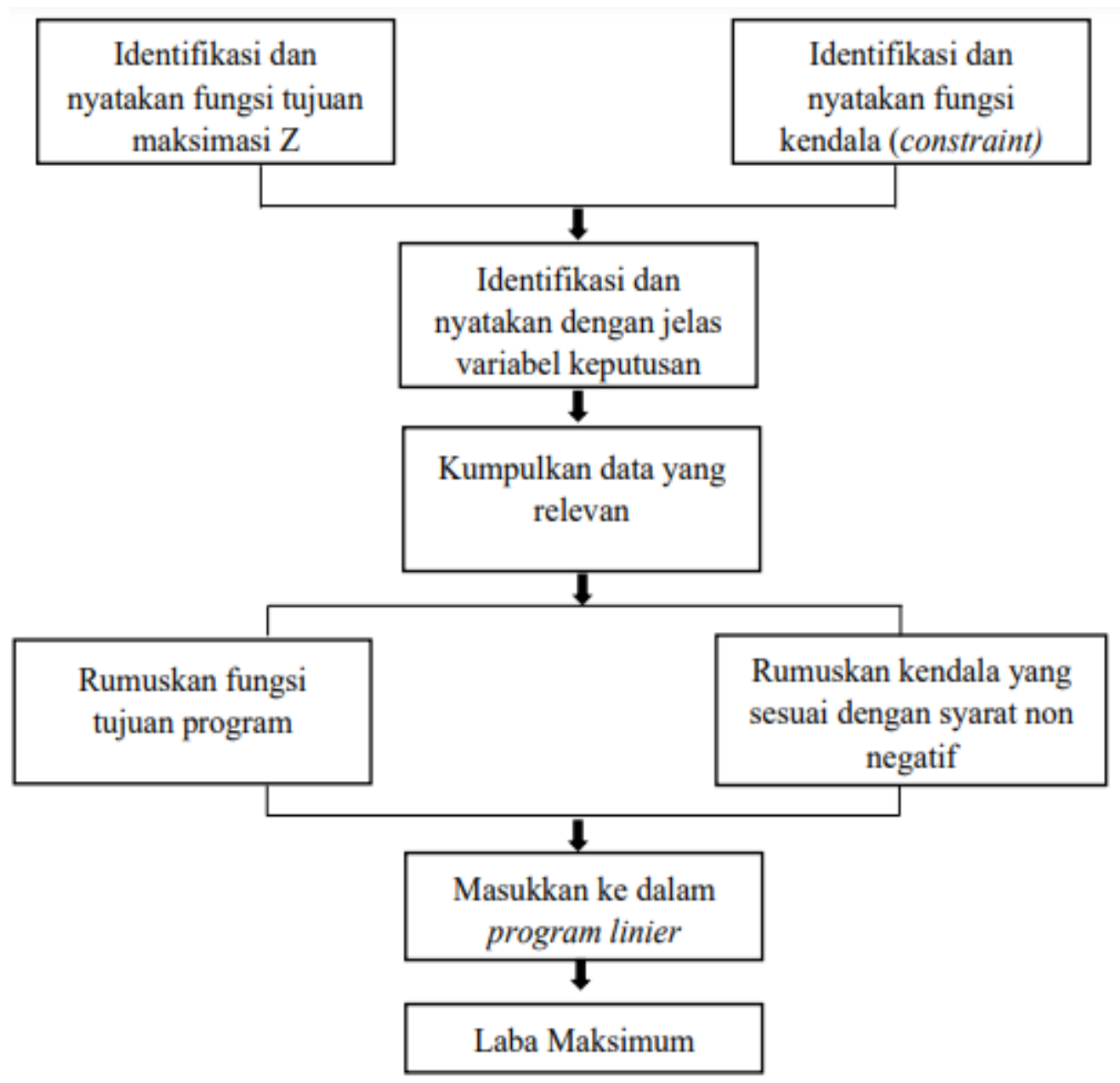

Gambar 1. Langkah-langkah Dalam Proses Optimasi 
Gambar diatas menjelaskan bahwa langkah pertama yang dilakukan yaitu mengidentifikasi dan nyatakan fungsi tujuan maksimasi $\mathrm{Z}$ serta fungsi kendala (constraint), identifikasi dan nyatakan variabel keputusan, mengumpulkan data yang relevan untuk penelitian, merumuskan fungsi tujuan program dan kendala yang sesuai dengan syarat non negatif, menginput data yang didapat mengenai fungsi tujuan dan kendala kedalam program linear programming menggunakan pendekatan linear programming dalam perencanaan kombinasi produk yang diproduksi pada UD. Serayu akan didapatkan hasil laba yang maksimal.

\section{METODE PENELITIAN}

Penelitian ini merupakan studi kasus mengenai optimalisasi produksi produk pada UD. Serayu. Penelitian ini merupakan penelitian deskriptif dengan pendekatan kuantitatif, untuk menganalisis permasalahan perusahaan mengenai produksi, melihat apakah produksi pada UD. Serayu di Tabanan ini sudah optimal atau belum. Penelitian ini dilakukan di UD. Serayu yaitu usaha dibidang bata expose di desa Pejaten, Kecamatan Kediri, Kabupaten Tabanan Provinsi Bali. Desa Pejaten merupakan salah satu daerah sentra industri kerajinan genteng, gerabah dan bata expose yang sebagaian besar masyarakatnya bekerja sebagai pengerajin olahan tanah liat.

Objek yang digunakkan dalam penelitian ini adalah produksi produk pada UD. Serayu sesuai dengan kriteria, kendala (constrains) yang dimiliki pada proses produksi produk pada UD. Serayu. Variabel penelitian ini adalah jenis dan jumlah produk; bahan baku per unit produk; lama proses produksi; kapasitas produksi; harga jual dan; hasil penjualan produk bata dalam unit

Jenis dan jumlah produk dalam penelitian ini adalah jenis produk yang dihasilkan yaitu Bata Expose Stick, Terakota Bata, Genteng Press dan Bubungan. Jumlah produk adalah banyaknya produk per unit yang dihasilkan oleh UD. Serayu dalam satu bulan. Bahan baku yang dimaksud adalah jumlah bahan baku tanah liat yang digunakan untuk memproduksi produk kerajinan bata selama satu bulan. Lama proses produksi dalam penelitian ini adalah waktu total yang diperlukan untuk mencetak masing - masing satu unit produk kerajinan bata. Kapasitas produksi adalah kemampuan maksimal produksi yang dimiliki oleh UD. Serayu selama satu bulan. Harga jual adalah harga per unit untuk masing-masing produk. Yang besarannya ditentukan oleh UD. Serayu yang diukur dengans satuan rupiah per unit produk. Laba per unit dalam penelitian ini merupakan hasil yang didapat dari penjualan produk per unit. Laba ini masih bruto, sehingga masih perlu dikurangi dengan biaya tetap dan juga biaya variabel, sehingga perhitungan analisis dalam satu bulan digunakan pendapatan bersih yang pengukurannya dengan satuan rupiah.

Data kualitatif dalam penelitian ini berupa gambaran umum tentang perusahaan dan kebijakan terkait proses produksi produk bata. Data kuantitatif berupa kuantitas jenis produk, harga jual, biaya tenaga kerja, penjualan perbulan dan kapasitas produksi yang dimiliki UD. Serayu. Sumber primer diperoleh langsung dari UD. Serayu dengan melalui wawancara mengenai kebijakan produksi produk dan lainnya sesuai dengan penelitian ini sedangkan sumber sekunder diperoleh dari laporan penjualan perbulan di UD. Serayu pada tahun 2019 serta 
beberapa pustaka tentang kombinasi produksi dan optimalisasi produksi serta jurnal dan buku terbitan lain yang mendukung pada penelitian ini.

Pengumpulan data dalam penelitian ini diperoleh dengan cara observasi dan wawancara. Observasi dalam penelitian ini observasi dilakukan terhadap dokumen perusahaan dalam hal ini terkait laporan penjualan tiap bulan serta proses produksi produk yang ada di UD. Serayu. Pengumpulan data dilakukan dengan wawancara langsung terhadap manajer UD. Serayu mengenai gambaran umum perusahaan dan kebijakan produksi produk bata pada UD. Serayu. Metode analisis data pada penelitian ini menggunakan model linear programming

\section{HASIL DAN PEMBAHASAN}

UD. Serayu dibangun dengan modal awal Rp. 75.000 .000 yang dipergunakan untuk membangun pabrik semi permanen, pembelian mesin cetak, tungku pembakaran, rak kayu dan juga peralatan lainnya. Pada awalnya tenaga kerja yang ada di UD. Serayu hanya berjumlah empat orang yang berasal dari luar kota yaitu tenaga kerja dari Lombok. Produk utama yang dijual adalah produk jenis Genteng Press dan Bubungan yang mampu menghasilkan omset awal lebih kurang sekitar Rp.30.000.000 per bulannya. Penjualan produk kerajinan bata berjalan dengan baik, lebih dari 20.000 produk terjual setiap bulannya.

Melihat adanya prospek peningkatan usaha, pemilik kemudian memutuskan untuk membeli beberapa mesin pada tahun 2018 dan menambah jumlah tenaga kerja menjadi 8 orang untuk mempercepat proses produksi dalam memenuhi kebutuhan pelanggan. Menurut Undang - Undang Republik Indonesia Nomor 20 Tahun 2008, UD. Serayu termasuk dalam usaha kecil. Usaha kecil memiliki kreteria kekayaan bersih antara Rp. 50.000.000,00 sampai dengan Rp. 500.000.000,00 tidak termasuk tanah dan bangunan tempat usaha atau memiliki hasil penjualan tahunan lebih dari Rp.300.000.000,00 sampai dengan Rp. 2.500.000.000,00. Saat ini UD. Serayu mampu meningkatkan omset penjualan menjadi lebih kurang $\mathrm{Rp}$. 100.000.000,00 per bulannya. Konsumen produk bata yang diproduksi oleh UD. Serayu saat ini berasal dari Gianyar (Ubud dan Sukawati), Tabanan, Negara (Pekutatan), Buleleng (Sukasada), Karangasem (Tianyar dan Sibetan), Badung (Kuta Selatan) dan Denpasar.

Bahan baku utama dari pembuatan Bata Expose Stick, Terakota Bata, Genteng Press dan Bubungan adalah tanah liat. Tanah liat yang digunakan oleh UD. Serayu ini didapatkan dari pemasok lokal yaitu dari daerah Tabanan. Supplier ini dipilih karena memiliki kualitas tanah liat yang baik serta harga yang dapat dinegosiasi. Bahan penolong pada proses pembuatan Bata Expose Stick, Terakota Bata, Genteng Press dan Bubungan adalah pasir paras.

Proses pertama yang dilakukan setelah tanah liat sampai ke perusahaan adalah memilah apakah sudah sesuai dengan standar perusahan. Kemudian tanah liat dipindahkan dari engkel truck menuju tempat yang telah disediakan. Berikutnya tanah liat yang sudah di pilih akan dimasukkan ke dalam mesin pencampur. Selanjutnya dilakukan pencampuran tanah liat dan batu paras. Pada proses ini tanah liat dan pasir paras akan dimasukkan kedalam mesin pencampur agar bahan tercampur dengan baik. Bahan baku tanah liat yang telah tercampur dengan pasir paras akan dimasukkan kedalam mesin penggiling dan menghasilkan bahan 
setengah jadi yang dapat dicetak sesuai dengan produk yang akan di produksi. Bahan setengah jadi ini berbentuk balok dan memiliki tekstur yang mudah dibentuk sehingga memudahkan pada saat proses pencetakan berlangsung. Adonan bata yang berbentuk balok selanjutnya dimasukkan kedalam mesin pencetakan untuk dibentuk sesuai dengan produk yang akan diproduksi. Tiap produk memiliki settingan penggunaan tatakan yang berbeda, sehingga waktu untuk memproses bahan setengah jadi untuk dicetak menjadi produk seperti Bata Expose Stick, Terakota Bata, Genteng Press dan Bubungan pun akan berbeda pula. Produk yang sudah dicetak selanjutnya akan dipindahkan ke rak pengeringan.

Bata yang telah dicetak perlu di masukkan kedalam rak pengeringan agar bentuknya tidak berubah. Pengeringan didalam rak ini memakan waktu yang berbeda-beda. Setelah produk yang telah dicetak sudah dirasa cukup kering kemudian masuk ke proses penjemuran. Pada tahap penjemuran ini sangat penting untuk memastikan bata yang akan masuk ke dalam tungku pembakaran nantinya benar-benar yang sudah kering dan siap untuk dibakar, sehingga bentuknya tidak berubah ketika dibakar. Kerajinan bata yang telah di jemur selanjutnya akan dimasukkan kedalam tungku pembakaran untuk mendapatkan hasil bata yang maksimal dan kuat. Proses menggunakan tungku pembakaran yang masih terbilang tradisional dengan bahan bakar serabut kelapa. Setelah bata selesai dibakar dari tungku pembakaran, kemudian akan didinginkan sebelum di kumpulkan pada tempat yang telah disediakan. Produk pada yang telah didinginkan dan diletakkan ditempat khusus selanjutnya akan melalui proses sortir sebelum sampai ke tangan pelanggan.

Tabel 1.

Klasifikasi Biaya Menurut Fungsi dan Perilaku Biaya dalam UD.Serayu

\begin{tabular}{|c|c|c|c|}
\hline Keterangan & Biaya Tetap & Biaya Variabel & Jumlah \\
\hline \multicolumn{4}{|l|}{ Biaya Produksi } \\
\hline Biaya Bahan Baku & & Rp $11,808,000.00$ & $\operatorname{Rp} 11,808,000.00$ \\
\hline Biaya Tenaga Kerja & & Rp $31,080,000.00$ & Rp 31,080,000.00 \\
\hline \multicolumn{4}{|l|}{ Langsung } \\
\hline \multicolumn{4}{|c|}{ Biaya Overhead Pabrik } \\
\hline $\begin{array}{l}\text { Biaya Tenaga Kerja } \\
\text { Tidak Langsung }\end{array}$ & $\operatorname{Rp} 4,000,000.00$ & & $\operatorname{Rp} 4,000,000.00$ \\
\hline $\begin{array}{l}\text { Biaya Bahan } \\
\text { Penolong }\end{array}$ & & Rp 15,523,200.00 & $\operatorname{Rp} 15,523,200.00$ \\
\hline Biaya Listrik & & Rp 51,600.00 & Rp 51,600.00 \\
\hline Biaya PAM & & Rp 51,600.00 & Rp 51,600.00 \\
\hline Biaya Depresiasi & Rp 1,195,666.67 & & Rp $1,195,666.67$ \\
\hline Mesin dan Peralatan & & & \\
\hline Biaya Depresiasi & $\operatorname{Rp} 246,495.31$ & & $\operatorname{Rp} 246,495.31$ \\
\hline Kendaraan & & & \\
\hline Biaya Pulsa & & Rp $100,000.00$ & Rp $100,000.00$ \\
\hline Biaya Transportasi & & Rp 500,000.00 & Rp 500,000.00 \\
\hline $\begin{array}{l}\text { Biaya Adm. dan } \\
\text { Umum }\end{array}$ & Rp $100,000.00$ & & $\operatorname{Rp} 100,000.00$ \\
\hline Total & Rp 5,542,161.98 & Rp 59,114,400.00 & Rp 64,656,561.98 \\
\hline
\end{tabular}

Biaya variabel merupakan metode untuk menentukan harga pokok produksi dengan cara mebebankan biaya-biaya produksi variabel saja ke dalam harga pokok 
produk yaitu terdiri dari biaya bahan baku, biaya tenaga kerja langsung dan biaya Overhead variabel. Penggolongan biaya UD. Serayu dibedakkan berdasar fungsi biaya dan perilaku biaya. Berdasarkan fungsinya biaya dapat dibedakan menjadi fungsi produksi, fungsi administrasi dan umum. Berdasarkan perilakunya biaya dapat dibedakan menjadi biaya tetap dan biaya variabel, sedangkan biaya semivariabel dan biaya semi tetap tidak dituliskan karena biaya dalam UD. Serayu dapat dikelompokkan menjadi biaya variabel dan biaya tetap.

Variabel keputusan dalam penelitian ini terdiri dari 4 variabel yang menunjukkan jumlah produksi bata yaitu X1 adalah Bata Expose Stick, X2 adalah Terakota Bata, X3 adalah Genteng Press dan X4 adalah Bubungan. Fungsi tujuan didalam penelitian ini yaitu maksimasi laba. Fungsi tujuan maksimasi laba adalah fungsi yang menunjukkan kontribusi laba per unit produk dalam satu kali produksi masing-masing produk yang dihasilkan oleh UD. Serayu. Laba per per unit dalam satu kali produksi masing-masing produk dihitung dalam satuan biji. Laba per unit produk dalam satu kali produksi adalah harga jual produk per unit yang dihasilkan dikurangi dengan biaya produksi produk per unit. Rincian perhitungan biaya produksi per unit dalam satu kali produksi dan rincian laba per masing-masing produk per unit dalam satu kali produksi yang dihasilkan dijabarkan pada tabel 2 dan 3

Tabel 2.

Biaya Produksi Variabel Per Unit Produk Bata Pada UD.Serayu

\begin{tabular}{|c|c|c|c|c|}
\hline Biaya & $\begin{array}{l}\text { Bata Expose } \\
\text { Stick }\end{array}$ & Terakota Bata & Genteng Press & Bubungan \\
\hline $\begin{array}{l}\text { Bahan Baku } \\
\text { (tanah liat per } \\
\text { unit produk) }\end{array}$ & Rp 200 & $\mathrm{Rp} 400$ & Rp 120 & Rp 160 \\
\hline $\begin{array}{l}\text { Tenaga Kerja } \\
\text { Langsung }\end{array}$ & Rp 500 & Rp 1.000 & Rp 300 & Rp 500 \\
\hline $\begin{array}{l}\text { Biaya Overhead } \\
\text { Pasir Paras (per } \\
\text { unit produk) }\end{array}$ & Rp 100 & $\mathrm{Rp} 200$ & Rp 60 & Rp 100 \\
\hline Listrik & Rp 1 & $\mathrm{Rp} 1$ & Rp 1 & $\mathrm{Rp} 1$ \\
\hline Air & Rp 1 & Rp 1 & Rp 1 & $\mathrm{Rp} 1$ \\
\hline Sambuk & Rp 155 & Rp 310 & Rp 93 & Rp 134 \\
\hline $\begin{array}{l}\text { Total Biaya Per } \\
\text { Unit }\end{array}$ & Rp 957 & Rp 1,912 & Rp 575 & Rp 896 \\
\hline
\end{tabular}

Sumber : UD.Serayu, 2019 
Tabel 3.

Laba Per Unit Produk Bata Pada UD.Serayu

\begin{tabular}{|c|c|c|c|c|}
\hline Keterangan & $\begin{array}{l}\text { Bata Expose } \\
\text { Stick }\end{array}$ & Terakota Bata & Genteng Press & Bubungan \\
\hline $\begin{array}{l}\text { Harga Penjualan } \\
\text { Per Unit Produk }\end{array}$ & Rp 1,650 & $\operatorname{Rp} 5,500$ & $\operatorname{Rp} 1,100$ & $\operatorname{Rp} 2,500$ \\
\hline $\begin{array}{l}\text { Biaya Produksi } \\
\text { Per Unit }\end{array}$ & Rp 957 & Rp 1,912 & Rp 575 & Rp 896 \\
\hline $\begin{array}{l}\text { Laba Per Unit } \\
\text { Produk }\end{array}$ & Rp 693 & $\operatorname{Rp} 3,588$ & Rp 525 & Rp 1,604 \\
\hline
\end{tabular}

Sumber : UD.Serayu, 2019

Harga penjualan per unit produk yang paling tinggi adalah harga jual Terakota Bata sebesar Rp.5.500 sedangkan penjualan yang paling rendah adalah Genteng Press sebesar Rp.1.100. Harga penjualan per unit produk Bata Expose Stick sebesar Rp. 1.650 dan harga penjualan per unit produk Bubungan sebesar Rp. 2.500. Biaya produksi per unit produk Terakota Bata merupakan biaya produksi yang paling tinggi yaitu sebesar Rp. 1.912 sedangkan biaya produksi Genteng Press merupakan yang paling rendah yaitu sebesar Rp.575 .

Biaya produksi per per unit Bata Expose Stick sebesar Rp. 957 dan biaya produksi per engkel Bubungan sebesar Rp. 896. Laba per unit produk Terakota Bata memberikan kontribusi laba tertinggi sebesar Rp.3.588 sedangkan laba Genteng Press memberikan kontribusi laba terendah sebesar Rp.525. Bata Expose Stick memberikan kontribusi laba sebesar Rp. 693 dan laba per unit produk Bubungan memberikan kontribusi laba sebesar Rp. 1.604. Fungsi tujuan UD.Serayu adalah

Maksimumkan $Z=693 X 1+3588 X 2+525 X 3+1604 X 4$

Keterangan

$\mathrm{Z}=$ total laba

$\mathrm{X} 1=$ jumlah produksi Bata Expose Stick

$\mathrm{X} 2=$ jumlah produksi Terakota Bata

$\mathrm{X} 3=$ jumlah produksi unit Genteng Press

X4 = jumlah produksi Bubungan

Fungsi batasan dalam penelitian ini terdiri dari fungsi batasan bahan baku tanah liat, fungsi batasan bahan penolong (paras), batasan lama proses produksi, batasan kapasitas produksi masing - masing produk dan fungsi batasan non negatif. Batasan bahan baku tanah liat dalam penelitian ini a dalah Satu engkel truck berisi tanah liat dengan berat $7.000 \mathrm{~kg}$. Untuk satu unit Bata Expose Stick memerlukan tanah liat sebesar $1 \mathrm{~kg}$. Satu unit Terakota Bata memerlukan tanah liat sebesar $2 \mathrm{~kg}$. Satu unit Genteng Press memerlukan tanah liat sebesar $0,6 \mathrm{~kg}$ dan satu unit Bubungan memerlukan tanah liat sebesar $0,8 \mathrm{~kg}$. Jumlah tanah liat yang tersedia dalam satu kali produksi adalah $6.000 \mathrm{~kg}$. Fungsi batasan untuk tanah liat adalah

$\mathrm{X} 1+2 \mathrm{X} 2+0,6 \mathrm{X} 3+0,8 \mathrm{X} 4 \leq 6000$ 
Satu unit produk Bata Expose Stick memerlukan batu paras sebesar 0,5 kg. Satu unit produk Terakota Bata memerlukan pasir paras sebesar $1 \mathrm{~kg}$. Satu unit produk Genteng Press memerlukan pasir paras sebesar 0,3 kg Satu unit produk Bubungan memerlukan pasir paras sebesar $0,4 \mathrm{~kg}$. Jumlah pasir paras yang tersedia dalam satu kali produksi sebesar $2.500 \mathrm{~kg}$. Fungsi batasan untuk pasir paras adalah

$0,5 \mathrm{X} 1+\mathrm{X} 2+0,3 \mathrm{X} 3+0,4 \mathrm{X} 4 \leq 2500$

Tabel 4.

Waktu Total Proses Produksi Bata

\begin{tabular}{lllll}
\hline \multicolumn{1}{c}{ Proses } & \multicolumn{1}{c}{$\begin{array}{c}\text { Bata Expose } \\
\text { Stick }\end{array}$} & $\begin{array}{c}\text { Terakota } \\
\text { Bata }\end{array}$ & $\begin{array}{c}\text { Genteng } \\
\text { Press }\end{array}$ & Pemugbug \\
\hline Pemilahan Bahan Baku & 0,5 & 0,5 & 0,5 & 0,5 \\
$\begin{array}{l}\text { Pencampuran Tanah Liat } \\
\text { dan batu paras }\end{array}$ & 1 & 1 & 1 & 1 \\
Proses Penggilingan & 2 & 2 & 2 & 2 \\
Pencetakan & 4 & 6 & 2 & 2 \\
Pengeringan di rak & 7,5 & 10,5 & 2,5 & 2,5 \\
Penjemuran & 18 & 18 & 4 & 9 \\
Pembakaran & 13 & 12 & 6 & 12 \\
Pendinginan & 2 & 2 & 2 & 2 \\
Sortir pengiriman & 1 & 1 & 1 & 1 \\
Total Waktu (jam) & 36 & 42 & 14 & 28 \\
Total Waktu Per Unit & 0,9 & 2 & 0,4 & 1 \\
Produk (Menit) & & & & \\
\hline
\end{tabular}

Sumber : UD.Serayu, 2019

Total waktu yang dibutuhkan untuk mengubah tanah liat menjadi satu unit produk Bata Expose Stick adalah selama 0,9 menit. Waktu yang dibutuhkan untuk mengubah tanah liat menjadi satu unit produk Terakota Bata adalah selama 2 menit. Waktu yang dibutuhkan untuk mengubah tanah liat menjadi satu unit produk Genteng Press adalah selama 0,4 menit. Waktu yang dibutuhkan untuk mengubah tanah liat menjadi satu unit produk Bubungan adalah 1 menit. Jam kerja yang tersedia selama satu kali produksi sebanyak 6.720 menit yang didapatkan dari jumlah tenaga kerja 8 orang dikalikan dengan jam kerja perhari yaitu 420 menit. Tenaga kerja bekerja selama 2 hari dalam satu kali produksi.

Jam kerja total $=$ jumlah tenaga kerja $\mathrm{x}$ jam kerja per hari $\mathrm{x}$ hari kerja per produksi Jam kerja total $=420 \times 8 \times 2=6.720$ menit.

Batasan untuk lama proses adalah

$0,9 \mathrm{X} 1+2 \mathrm{X} 2+0,4 \mathrm{X} 3+\mathrm{X} 4 \leq 6720$ 
Tabel 5.

Kapasitas Maksimal Produksi Masing - Masing Produk Pada UD. Serayu

\begin{tabular}{llllll}
\hline Keterangan & $\begin{array}{l}\text { Bata } \\
\text { Stick }\end{array}$ & Expose & Terakota Bata & Genteng Press & Bubungan \\
\hline $\begin{array}{l}\text { Kapasitas } \\
\text { Maksimal Produk }\end{array}$ & 1,800 & 1,500 & 800 & 1,200 \\
\hline
\end{tabular}

Sumber : UD.Serayu, 2019

Berdasarkan data kapasitas maksimal yang dapat di produksi pada masingmasing produk bata berbeda-beda. Produk Bata Expose Stick mempunyai kapasitas maksimal sebesar 1.800 biji dalam satu kali produksi. Produk Terakota Bata mempunyai kapasitas maksimal sebesar 1.500 biji dalam satu kali produksi. Produk Genteng Press mempunyai kapasitas maksimal sebesar 800 biji. Produk Bubungan mempunyai kapasitas maksimal sebesar 1.200 biji.

Tabel 6.

Hasil Optimalisasi UD. Serayu

\begin{tabular}{|c|c|c|c|c|}
\hline Keterangan & $\mathrm{X1}$ & $\mathrm{X} 2$ & $\mathrm{X3}$ & $\mathrm{X} 4$ \\
\hline $\begin{array}{l}\text { Jumlah Optimal } \\
\text { (biji) }\end{array}$ & 560 & 1500 & 800 & 1200 \\
\hline Lower bound & 0 & 1386 & 415.8 & 554.4 \\
\hline $\begin{array}{l}\text { Upper bound } \\
\text { Laba maksimum }\end{array}$ & Infinity & Infinity & $\begin{array}{l}\text { Infinity } \\
\text { Rp. 8,1 }\end{array}$ & Infinity \\
\hline
\end{tabular}

Sumber : Data Diolah, 2020

Tabel 6. menunjukkan laba maksimal satu kali produksi bata sebesar Rp. 8,114,880.00. Dengan kombinasi produksi optimal yaitu Bata Expose Stick (X1) sebanyak 560 biji, Terakota Bata (X2) sebanyak 1,500 biji, Genteng Press (X3) = 800 biji dan Bubungan $(\mathrm{X} 4)=1,200$ biji. Laba maksimal perusahaan didapatkan dengan memproduksi Bata Expose Stick sebanyak 560 biji, Terakota Bata sebanyak 1,500 biji , Genteng Press 800 biji, Bubungan sebanyak 1,200 biji dengan laba maksimum Rp.8,114,880. Nilai lower bound dan upper bound menunjukkan batas bawah dan batas jumlah satuan masing-masing produk yang dapat diproduksi oleh perusahaan. Nilai lower bound X1 menunjukkan bahwa nilai permintaan minimal yang dapat dilayani perusahaan untuk produk Bata Expose Stick yaitu sebanyak 0 biji artinya perusahaan dapat memilih untuk tidak memenuhi permintaan Bata Expose Stick. Nilai upper bound menunjukkan bahwa perusahaan dapat melayani permintaan Bata Expose Stick maksimal sebanyak 875 biji

Nilai lower bound X2 menunjukkan bahwa nilai permintaan minimal yang dapat dilayani perusahaan untuk Terakota Bata sebanyak 1386 biji. Nilai upper bound menunjukkan bahwa perusahaan dapat memenuhi permintaan Terakota Bata maksimal sebanyak tidak terbatas. Nilai lower bound X3 menunjukkan bahwa nilai permintaan minimal yang dapat dilayani perusahaan untuk Genteng Press adalah sebanyak 415 biji. Nilai upper bound menunjukkan bahwa perusahaan dapat melayani permintaan produk Genteng Press maksimal sebanyak tidak terbatas. 
Nilai lower bound $X 4$ menunjukkan bahwa nilai permintaan minimal yang dapat dilayani untuk produk Bubungan adalah sebanyak 554 biji. Nilai upper bound menunjukkan bahwa perusahaan dapat melayani permintaan produk Bubungan sebanyak tidak terbatas.

Solusi optimal atas fungsi tujuan dan fungsi batasan pada UD. Serayu didapatkan pada iterasi ke-5 seperti yang ditunjukkan oleh tabel 7

Tabel 7.

Simpleks Linear Programming Iteration 5

\begin{tabular}{llllllllllllll}
\hline \multicolumn{10}{l}{ Iteration 5 } \\
\hline 0 & slack 1 & 1000 & 0 & 0 & 0 & 0 & 1 & -2 & 0 & 0 & 0 & 0 & 0 \\
693 & X1 & 560.0 & 1 & 0 & 0 & 0 & 0 & 2 & 1 & 0 & -2 & -0.6 & -0.8 \\
0 & slack 3 & 1696.0 & 0 & 0 & 0 & 0 & 0 & -1.8 & 0 & 1 & -0.2 & 0.14 & -0.28 \\
0 & slack 4 & 1240.0 & 0 & 0 & 0 & 0 & 0 & -2 & 0 & 0 & 2 & 0.6 & 0.8 \\
3588 & $\mathrm{X} 2$ & 1500 & 0 & 1 & 0 & 0 & 0 & 0 & 0 & 0 & 1 & 0 & 0 \\
525 & $\mathrm{X} 3$ & 800 & 0 & 0 & 1 & 0 & 0 & 0 & 0 & 0 & 0 & 1 & 0 \\
1604 & $\mathrm{X} 4$ & 1200 & 0 & 0 & 0 & 1 & 0 & 0 & 0 & 0 & 0 & 0 & 1 \\
& zj & $8,144,880$ & 693 & 3588 & 525 & 1604 & 0 & 1386 & 0 & 0 & 2202 & 109.2 & 1049.6
\end{tabular}

Sumber : Data Diolah, 2020

Tabel 8 menunjukkan nilai hasil optimalisasi yang terdiri dari nilai dual value, nilai surplus/slack, nilai lower bound, dan nilai upper bound dari fungsi batasan. Nilai dual value menunjukkan tambahan laba dari batasan pada laba usaha. Nilai surplus/slack menunjukkan nilai sisa atau nilai kekurangan dari setiap fungsi batasan. Nilai lower bound menunjukkan nilai batas bawah atau nilai minimal dari setiap fungsi batasan yang harus dimiliki perusahaan. Nilai upper bound menunjukkan nilai batas atas atau nilai maksimal dari setiap fungsi batasan yang dapat digunakan oleh perusahaan dalam proses produksi.

Tabel 8.

Optimalisasi (Ranging) UD. Serayu

\begin{tabular}{lllll}
\hline Keterangan & Dual Value & Slack/Surplus & Lower bound & Upper bound \\
\hline $\begin{array}{l}\text { Bahan Baku } \\
\text { (tanah liat) }\end{array}$ & 0 & 1000 & 5000 & Infinity \\
$\begin{array}{l}\text { Bahan Penolong } \\
\text { (pasir paras) }\end{array}$ & 1386 & 0 & 2220 & 3000 \\
$\begin{array}{l}\text { Lama Proses } \\
\text { Kapasitas Maks. }\end{array}$ & 0 & 0 & 5024 & Infinity \\
X1 & 0 & 0 & 560 & Infinity \\
Kapasitas Maks. & 2202 & 1252 & 880 & 1780 \\
$\begin{array}{l}\text { X2 } \\
\text { Kapasitas Maks. }\end{array}$ & 109.2 & 0 & 0 & 1733.33 \\
$\begin{array}{l}\text { X3 } \\
\text { Kapasitas Maks. }\end{array}$ & 1049.6 & 0 & 0 & 1900 \\
X4 & & & &
\end{tabular}

$\mathrm{X} 4$

Sumber: Data Diolah, 2020

Penambahan 1 kilogram tanah liat tidak akan memberikan tambahan kontribusi laba karena dual value nya 0 . Nilai surplus/slack sebesar 1,000 berarti terdapat sisa tanah liat sebesar $1,000 \mathrm{~kg}$ atau dapat dikatakan tanah liat yang tersedia 
lebih banyak dari yang sebenarnya dibutuhkan oleh perusahaan. Jumlah minimal tanah liat yang harus dimiliki oleh perusahaan adalah sebesar $5,000 \mathrm{~kg}$

Penambahan 1 kilogram pasir paras akan memberikan tambahan kontribusi laba sebesar Rp. 1,386 karena dual value nya 1,386. Nilai slack/surplus sebesar 0 berarti tidak terdapat sisa pasir paras atau dapat dikatakan pasir paras yang tersedia sudah sesuai dengan yang dibutuhkan perusahaan. Jumlah minimal pasir paras yang harus dimiliki perusahaan adalah sebesar $2,220 \mathrm{~kg}$.

Penambahan setiap 1 menit kerja tidak akan memberikan kotnribusi laba karena dual valuenya 0. Angka 1,696 pada kolom slack/surplus menunjukkan bahwa terdapat sisa waktu dalam satu kali produksi sebanyak 1,696 menit. Jumlah minimal jam kerja yang harus dimiliki perusahaan adalah 5,024 menit dalam satu kali produksi. Perusahaan melakukan produksi dalam satu bulan sebanyak dua belas kali , maka kombinasi optimal produksi dalam satu bulan untuk produk Bata Expose Stick adalah sebanyak 6,720 biji , produk Terakota Bata sebanyak 18,000 biji , produk Genteng Press sebanyak 9,600 biji dan produk Bubungan sebanyak 14,400 biji.

Perhitungan laba yang dilakukan UD. Serayu untuk menghitung keuntungan bersih usahanya belum mempertimbangkan aspek biaya - biaya diluar biaya yang berhubungan langsung dengan biaya produksi. Hal ini membuat UD. Serayu belum mengetahui laba bersih yang dihasilkan dari produksinya. Biaya yang belum diperhitungkan ke dalam laba rugi perusahaan adalah biaya gaji pemilik perusahaan, biaya depresiasi kendaraan serta biaya depresiasi kendaraan. Proyeksi terhadap laba rugi UD. Serayu ini dilakukan untuk mengetahui perbandingan terhadap laba perusahaan jika berproduksi sesuai dengan pesanan dan berproduksi sesuai dengan hasil optimalisasi produksi.

Biaya yang timbul dengan adanya peningkatan produksi perusahan yaitu terkait dengan biaya pemasaran berupa pulsa dan biaya pengiriman atau biaya transportasi. Biaya pulsa diasumsikan meningkat sebesar 10 persen. Biaya pulsa digunakan untuk menawarkan produk ke market place yang ada. b) Biaya transportasi diasumsikan meningkat sebesar 20 persen yang dipergunakan untuk mengantar produk ke konsumen. UD. Serayu saat ini belum memiliki ijin usaha, sehingga belum melakukan pembayaran pajak. Perhitungan laba rugi pada penelitian ini menghitung pajak final sebesar satu persen berdasarkan peraturan Mentri Republik Indonesia Nomor 46 Tahun 2013 Pasal 3 ayat 1 seperti yang ditunjukkan oleh tabel 9.

Tabel 9.

Perbandingan Biaya dan Laba Bersih UD.Serayu

\begin{tabular}{|c|c|c|}
\hline Keterangan & Produksi Perbulan & $\begin{array}{l}\text { Kombinasi } \\
\text { Optimal }\end{array}$ \\
\hline Total Pendapatan Penjualan & Rp $148,560,000.00$ & Rp $156,648,000.00$ \\
\hline Biaya Produksi & -Rp 59,114,400.00 & -Rp 59,979,440.00 \\
\hline Variabel Biaya Overhead & $-R p 5,542,161.98$ & -Rp 5,542,161.98 \\
\hline Tetap, administrasi dan umum & & \\
\hline Pajak Final (1\%) & $-\operatorname{Rp} 1,485,600.00$ & -Rp $1,566,480.00$ \\
\hline Laba bersih setelah pajak & $\operatorname{Rp} 82,417,838.02$ & $\operatorname{Rp} 89,559,918.02$ \\
\hline
\end{tabular}

Sumber: Data Diolah, 2020 
Peningkatan Penjualan $=\frac{\text { Total Penjualan KPO-Total Penjualan PSP }}{\text { Total Penjualan PSP }} \times 100 \%$

Peningkatan Penjualan $=\frac{\text { Rp 156.648.000-Rp 148.560.000 }}{\text { Rp 148.560.000 }} \times 100 \%$

Peningkatan Penjualan $=5,44 \%$

Proyeksi selisih penjualan bila UD.Serayu berproduksi sesuai produksi bulanan dan bila berproduksi sesuai jumlah kombinasi optimal adalah sebesar Rp. $8,088,000.00$. Jumlah tersebut menunjukkan terjadi peningkatan penjualan sebesar 5.44 persen bila perusahaan berproduksi sesuai jumlah kombinasi optimal dibandingkan bila perusahaan berproduksi sesuai produksi bulanan.

Peningkatan Laba Bersih $=\frac{\text { Laba Bersih KPO }- \text { Laba Bersih PSP }}{\text { Laba Bersih PSP }} \times 100 \%$

Peningkatan Laba Bersih $=\frac{\mathrm{Rp} 89.559 .918,02-\mathrm{Rp} 82.417 .838,02}{\mathrm{Rp} \mathrm{82.417.838,02}} \times 100 \%$

Peningkatan Laba Bersih $=8,67 \%$

Proyeksi selisih dari laba bersih jika UD.Serayu berproduksi sesuai produksi bulanan dan bila perusahaan berproduksi sesuai dengan jumlah kombinasi produk optimal adalah sebesar $\mathrm{Rp}$ 7.142.080 Jumlah tersebut menggambarkan terjadi peningkatan laba bersih sebesar 8,67 persen bila perusahaan berproduksi sesuai jumlah kombinasi optimal dibandingkan bila perusahaan berproduksi sesuai produksi bulanan.

Penelitian ini dapat menjadi rujukan untuk penelitian terkait kombinasi produksi optimal. Penelitian ini menggabungkan analisis linear programming dan perhitungan laba bersih. Analisis linear programming ini berfungsi untuk menentukan kombinasi produksi optimal dengan adanya sumber daya yang terbatas. Analisis proyeksi laba bersih membandingkan laba usaha jika tidak menggunakan kombinasi produk optimal dan jika menggunakan kombinasi produk optimal dipergunakan oleh pihak perusahaan khususnya manajemen untuk mengambil keputusan dalam melakukan produksi. Penelitian ini dapat menjadi sumber pengetahuan tambahan bagi perusahan dalam menentukan jumlah produksi optimal dengan keterbatasan sumber daya yang ada dengan bantuan alat analisis linear programming. Penelitian ini memberikan informasi mengenai penggunaan software POM-QM for Windows untuk penghitungan optimalisasi produksi.

\section{SIMPULAN}

Kombinasi produksi optimal pada produk di UD. Serayu dapat tercapai dengan memproduksi Bata Expose Stick sebanyak 6,720 biji, Terakota Bata sebanyak 18,000 biji, Genteng Press sebanyak 9,600 biji dan Bubungan sebanyak 14,400 biji. Laba bersih yang dihasilkan oleh UD. Serayu dalam produksi selama satu bulan adalah Rp. 82,417,838.02 sedangkan laba bersih yang dapat dihasilkan oleh UD. Serayu bila berproduksi pada jumlah kombinasi produk optimal adalah 
sebesar Rp.89,559,918.02. Peningkatan laba bersih adalah sebesar 8,67 persen. Untuk dapat menghasilkan keuntungan yang maksimal UD. Serayu sebaiknya berproduksi sesuai dengan kombinasi produksi optimal. Perusahaan sebaiknya memproduksi Bata Expose Stick sebanyak 6,720 biji, Terakota Bata sebanyak 18,000 biji, Genteng Press sebanyak 9,600 biji dan Bubungan sebanyak 14,400 biji dengan menghasilkan laba sebesar Rp. 89,559,918.02.

Penelitian selanjutnya mengenai optimalisasi produksi disarankan untuk menerapkan proses linear programming pada perusahaan berbeda baik barang maupun jasa, yang memiliki keterbatasan sumber daya untuk menghasilkan produksi optimal dengan laba maksimal. Serta melakukan analisis tambahan berupa proyeksi laba bersih usaha jika tidak dapat menerapkan optimalisasi dan jika dapat menerapkan optimalisasi.

\section{REFERENSI}

Akpan, N. P., \& Iwok, I. A. (2016). Application of Linear Programming for Optimal Use of Raw Materials in Bakery. International Journal of Mathematics and Statistics Invention (IJMSI), 4(8), 51-57. www.ijmsi.org

Anugrahwaty, R., \& Azmi, F. (2017). Analisis Prediksi Perencanaan Produksi dengan Fuzzy Logic Tsukamoto. Sinkron: Jurnal Dan Penelitian Teknik Informatika, $1(2)$, https://jurnal.polgan.ac.id/index.php/sinkron/article/view/29

Aprilyanti, S. (2019). Optimasi Keuntungan Produksi Pada Industri Kayu PT . Indopal Harapan Murni Menggunakan Linear. Jurnal Penelitian Dan Aplikasi Sistem \& Teknik Industri (PASTI), 8(1), 1-8.

Baidya, A., Bera, U. K., \& Maiti, M. (2016). The Grey Linear Programming Approach And Its Application To Multi-Objective Multi-Stage Solid Transportation Problem. Opsearch, 53(3), 500-522. https://doi.org/https://doi.org/10.1007/s12597-015-0246-1

Chandrawat, R. K., Kumar, R., Garg, B. P., Dhiman, G., \& Kumar, S. (2017). An Analysis of Modeling and Optimization Production Cost Through Fuzzy Linear Programming Problem with Symmetric and Right Angle Triangular Fuzzy number. Advances in Intelligent Systems and Computing, 546(1), 197211. https://doi.org/https://doi.org/10.1007/978-981-10-3322-3_18

Du, J., Yu, R., Chu, X., Feng, J., \& Lu, G. (2018). Computation Offloading and Resource Allocation in Vehicular Networks Based on Dual-side Cost Minimization. IEEE Transactions on Vehicular Technology, 68(2), 1079. https://doi.org/10.1109/tvt.2018.2883156

Ehmke, J. F., Campbell, A. M., \& Barret, W. T. (2018). Optimizing for total costs in vehicle routing in urban areas. Transportation Research Part E: Logistics 
and Transportation Review, 116(1), 242-265. https://doi.org/https://doi.org/10.1016/j.tre.2018.06.008

Eunike, A. T. (2018). Perencanaan Produksi dan Pengendalian Persediaan. Malang: UB Press.

Ganzer, P. P., Chais, C., \& Olea, P. M. (2017). Product, process, marketing and organizational innovation in industries of the flat knitting sector. RAI Revista de Administração e Inovação, 14(4), 321-332. https://doi.org/10.1016/j.rai.2017.07.002

Georgiadis, G. P., Elekidis, A. P., \& Georgiadis, M. C. (2019). Optimization-based scheduling for the process industries: From theory to real-life industrial applications. Processes, 7(7), 1. https://doi.org/10.3390/pr7070438

Hilman, M. (2016). Optimasi Jumah Produksi Produk Furniture Pada PD . Surya Mebel Di Kecamatan Cipaku Dengan Metode Linier Programming. Jurnal Media Teknologi, 03(01), 85-97. https://scholar.googleusercontent.com/scholar?q=cache:f91BzsvVu1YJ:schol ar.google.com/+2.\%09Maman+Hilman, $+(2016)+$ penelitian+ini+tentang+"O ptimasi+Jumlah+Produksi+Produk+Furniture+pada+PD.+Surya+Mebel+di+ Kecamatan+Cipaku+Dengan+Metode+Linear+Programming”\&h

Hosseini Jey, H. R., Javanshir, H., \& Mohajeri, A. (2017). A two-stage production planning model for perishable products under uncertainty. Uncertain Supply Chain Management, 5(3), 201-214. https://doi.org/10.5267/j.uscm.2017.1.002

Indah, D. R., \& Sari, P. (2019). Penerapan Model Linear Programming Dalam Memperoleh Keuntungan Maksimal ( Studi Kasus Pada Usaha Angga Perabot ). Jurnal Manajemen Inovasi, 10(2), 98-115.

Jain, A. K., Saxena, H., Bhardwaj, R., Jagannadha Rao, G. V. V., \& Siddharth Nanda, C. (2020). Application of linear programming for profit maximization of a Pharma Company. Journal of Critical Reviews, 7(12), 1118-1123. https://doi.org/10.31838/jcr.07.12.195

Khan, I. U., \& Faisal, R. (2021). Minimum-Cost Capacitated Fuzzy Network, Fuzzy Linear Programming Formulation, And Perspective Data Analytics To Minimize The Operations Cost Of American Airlines. Soft Computing, 25(1), pages1411-1429. https://link.springer.com/article/10.1007/s00500-02005228-5

Kim, T., \& Glock, C. H. (2018). Production planning for a two-stage production system with multiple parallel machines and variable production rates. International Journal of Production Economics, 196(9), 284-292. 
https://doi.org/10.1016/j.ijpe.2017.11.018

Kimutai, I., Maina, P., \& Makokha, A. (2019). Energy Optimization Model Using Linear Programming for Process Industry: A Case Study of Textile Manufacturing Plant in Kenya. International Journal of Energy Engineering, 9(2), 45-52. https://doi.org/10.5923/j.ijee.20190902.03

Krisnadewi, N. P., \& Setiawan, P. Y. (2018). Optimalisasi Produksi Pada Usaha Kecil Kripik Terry Di Desa Nyanglan Kaja, Kecamatan Tembuku. E-Jurnal Manajemen Unud, 7(11), $6011 \quad-\quad 6040$. https://doi.org/https://doi.org/10.24843/EJMUNUD.2018.v07.i11.p08

Lauinger, D., Caliandro, P., Van herle, J., \& Kuhn, D. . A. (2016). Linear Programming Approach to The Optimization of Residential Energy Systems. Journal of Energy Storage, 7(1), 24-37. https://doi.org/https://doi.org/10.1016/j.est.2016.04.009

Mohd Baki, S., \& Cheng, J. K. (2020). A Linear Programming Model for Product Mix Profit Maximization in A Small Medium Enterprise Company. International Journal of Industrial Management, 6(1), 64-73. https://doi.org/10.15282/ijim6120205330

Murni, M., Sihotang, T. H., \& Marbun, V. N. (2016). Perancangan Sistem Perencanaan Jumlah Produksi Roti Menggunakan Metode Fuzzy Mamdani. Jurnal Mantik Penusa, Jurnal Manajemen Dan Informatika Pelita Nusantara, 20(1), 48-54. http://ejurnal.pelitanusantara.ac.id/index.php/mantik/article/download/211/123

Nazari, A., Thiruvady, D., Aleti, A., \& Moser, I. (2016). A Mixed Integer Linear Programming Model For Reliability Optimisation In The Component Deployment Problem. Journal of the Operational Research Society, 67(8), 1050-1060. https://doi.org/https://doi.org/10.1057/jors.2015.119

Ogbeide, D., \& Ejechi, J. O. (2018). Product Mix Optimization in the Manufacturing Industry: A Linear Product Mix Optimization in the Manufacturing Industry: A Linear Programming Approach. Journal of Economics and Finance, 2(2), 263-275.

Oladejo, N. K., Abolarinwa, A., Salawu, S. O., Lukman, A. F., \& Bukari, H. I. (2019). Optimization principle and its' application in optimizing landmark university bakery production using linear programming. International Journal of Civil Engineering and Technology, 10(2), 183-190.

Parlesak, A., Tetens, I., Jensen, J. D., Smed, S., Blenkuš, M. G., Rayner, M., Darmon, N., \& Robertson, A. (2016). Use of linear programming to develop cost- minimized nutritionally adequate health promoting food baskets. PLoS 
ONE, 11(10), 1-19. https://doi.org/10.1371/journal.pone.0163411

Putri, N. P. Y., \& Nurcaya, I. N. (2020). Material Requirement Planning Analysis of Body Massage Cream Products In CV. Denara Duta Mandiri In Denpasar. American Journal of Humanities and Social Sciences Research (AJHSSR), 4(5), 97-106.

Qiu, Y., Qiao, J., \& Pardalos, P. M. (2019). Optimal production, replenishment, delivery, routing and inventory management policies for products with perishable inventory. Omega, Elsevier, 82(C), 193-204.

Rizkya, I., Hidayati, J., Syahputri, K., Sari, R. M., Siregar, I., Siregar, K., \& Utaminingrum, J. (2019). Measurement of Supply Chain Performance in Manufacturing. Journal of Physics: Conference Series, 1230(1), 1-10. https://doi.org/10.1088/1742-6596/1230/1/012056

Romanova, A. A. (2019). Minimizing resource cost in project scheduling problem with accumulative resources. Journal of Physics: Conference Series, 1260(8), 1. https://doi.org/10.1088/1742-6596/1260/8/082005

Sadeghian, H. R., \& Ardehali, M. M. (2016). A Novel Approach For Optimal Economic Dispatch Scheduling Of Integrated Combined Heat And Power Systems For Maximum Economic Profit And Minimum Environmental Emissions Based On Benders Decomposition. Journal Energy, 102(1), 10-23. https://doi.org/https://doi.org/10.1016/j.energy.2016.02.044

Salim, A., \& Santoso, I. B. (2018). Optimasi Produksi Beton Ready Mix dengan Metode Linear Programming. Jurnal Mitra Teknik Sipil, 1(1), 65-71.

Sinaga, P. R. (2016). Perancangan Optimasi Produksi Sarung Tangan Menggunakan Linear Programing Pada PT . Smart Glove Indonesia. Jurnal Informasi Dan Teknologi Ilmiah (INTI), 11(9), 44-50.

Sudhana, P. (2017). Optimasi Jumlah Kamar Pada Pembangunan Budget Hotel Dengan Metode Integer Linear Programming. Seminar Ilmu Nasional Terapan. (SNITER), 1(1), 1-8.

Sudjaja, G., \& Santoso, I. B. (2018). Optimasi Pendistribusian Tanah Dengan Menggunakan Metode Linear Programming. JMTS: Jurnal Mitra Teknik Sipil, 1(1), 92. https://doi.org/https://doi.org/10.24912/jmts.v1i1.2246

Supardi. (2020). The Effect Of Production Supervisory Competency Of Heavy Equipment Operators Performance At The Mining Contractor Of Pt . Riung Mitra Lestari. American Journal of Humanities and Social Sciences Research (AJHSSR), 164(2), 159-164. 
Supriyo, P. T. (2019). Kereta Api Berdasar Pemrograman Linear Integer. Prosiding Sendika, 5(2), 241-245.

Wang, S., Bi, S., \& Zhang, Y. J. A. (2018). Demand Response Management For Profit Maximizing Energy Loads In Real-Time Electricity Market. IEEE Transactions on Power Systems, 33(6), 6387-6396. https://doi.org/https://doi.org/10.1109/TPWRS.2018.2827401

Woubante, G. W. (2017). The Optimization Problem of Product Mix and Linear Programming Applications: Case Study in the Apparel Industry. Open Science Journal, 2(2), 1. https://doi.org/10.23954/osj.v2i2.853

Yucesan, M. (2017). Aggregated Production Planning in Sofa Production By Preemptive Goal Programming Approach. Journal Of Business Research Turk, 9(2), 184-196. 